\title{
Energy Storage Options for Voltage Support in Low-Voltage Grids with High Penetration of Photovoltaic
}

\author{
Marra, Francesco; Tarek Fawzy, Y. ; Bülo, Thorsten; Blaži, Boštjan
}

Published in:

Proceedings of IEEE PES Innovative Smart Grid Technologies (ISGT)

Publication date:

2012

Link back to DTU Orbit

Citation (APA):

Marra, F., Tarek Fawzy, Y., Bülo, T., \& Blaži, B. (2012). Energy Storage Options for Voltage Support in LowVoltage Grids with High Penetration of Photovoltaic. In Proceedings of IEEE PES Innovative Smart Grid Technologies (ISGT) IEEE.

\section{General rights}

Copyright and moral rights for the publications made accessible in the public portal are retained by the authors and/or other copyright owners and it is a condition of accessing publications that users recognise and abide by the legal requirements associated with these rights.

- Users may download and print one copy of any publication from the public portal for the purpose of private study or research.

- You may not further distribute the material or use it for any profit-making activity or commercial gain

- You may freely distribute the URL identifying the publication in the public portal

If you believe that this document breaches copyright please contact us providing details, and we will remove access to the work immediately and investigate your claim. 


\title{
Energy Storage Options for Voltage Support in Low-Voltage Grids with High Penetration of Photovoltaic
}

\author{
Francesco Marra, Y. Tarek Fawzy, Thorsten Bülo and Boštjan Blažič
}

\begin{abstract}
The generation of power by photovoltaic (PV) systems is constantly increasing in low-voltage (LV) distribution grids, in line with the European environmental targets. To cope with the effects on grid voltage profiles during high generation and low demand periods, new solutions need to be established. In the long term, these solutions should also aim to allow further more PV installed capacity, while meeting the power quality requirements. In this paper, different concepts of energy storage are proposed to ensure the voltage quality requirements in a $L V$ grid with high $P V$ penetration. The proposed storage concepts can cooperate with reactive power methods and can be used to avoid grid reinforcement and active power curtailment. For the study, a residential LV grid with high share of PV generation is used. Simulation results show substantial benefits for the $L V$ feeders operation, as well as an increased potential for local consumption.
\end{abstract}

Index Terms - Active distribution grids, energy storage, low voltage grids, reactive power control, voltage rise mitigation

\section{INTRODUCTION}

$\mathrm{T}$ HE renewable energy sector has experienced a large growth in the last decade. The need of fulfilling the European environmental targets [1] aiming for an increased sustainability have led to important advances in solar technologies. Lately, these advances are also pushed by the research on smart grids on active distribution networks [2].

Especially LV grids have seen in the last few years an exponential increase of PV installations at the residential level. Increasing the PV penetration is a fundamental target which however poses new challenges for the operation of distribution grids [3]-[4]. One of the issues to cope with is the grid voltage variation along a LV feeder, due to high generation and low demand periods [5]. Historically, LV grids have been planned to deliver unidirectional power to the loads. With distributed generation such as PV, the situation of power flow inversion is more likely to happen [6]. This can lead to overvoltage problems at the PV generator point of connection (PCC) that in extreme cases requires the curtailment of active power [7]. The European power quality standard EN 50160 states that during each period of one week, $95 \%$ of the 10 -minutes average voltage

The authors acknowledge the co-funding of the European Commission in the $7^{\text {th }}$ Framework Programme (FP7) through grant agreement No. TREN/FP7EN/239511/METAPV.

Mr. F. Marra, Mr. Y. T. Fawzy, and Mr. T. Bülo are with the Department of Technology Development, SMA Solar Technology AG, Sonnenallee 1, 34266 Niestetal, Germany (e-mail: fm@elektro.dtu.dk).

Mr. Blažič is with the Department of Electrical Engineering, University of Ljubljana, Slovenia. values shall be within the range of $U_{n}+/-10 \%$, where $U_{n}$ is the nominal voltage [8]. Central coordination and local voltage support approaches have been described by Carvalho et Al. in [9] to deal with voltage variations. The first one can provide voltage support, using a communication infrastructure for the real time monitoring and the coordination of individual PV generators. An example is the use of controllable tap-changer $10 / 0.4 \mathrm{kV}$ transformers to adjust the voltage setting as required; however, this adjustment changes the operational condition of all LV feeders supplied by the same transformer. Also, the voltage adjustment is only possible if the grid is equipped with such transformers, which is rather uncommon in the real case.

Local methods based on reactive power for voltage control have been the most used so far, as they are implemented on each PV inverter that can work independently [10]-[11].

Reactive power methods do not necessarily require a supervisory control and communication, as the single PV inverters are able to adapt in real time to the actual local voltage situation [12], however, the amount of reactive power needed for voltage support will considerably rise up with the PV penetration, thus the rethinking of solutions including storage for voltage support is necessary [13].

Storage solutions can play an important role in relation to the national electricity tariff systems of the different European countries [14]. Considering the case of Germany, the "self-consumption" tariff (EEG) is already applied from 2009 to the residential PV sector [15]. Though the selfconsumption act is planned to be amended, a general incentive for private consumption will persist [16].

The need of storage for grid support will lead to a higher synergy between PV power and electricity consumers, giving the opportunity of self-consumption.

In this paper, different storage concepts for mitigating voltage variations in LV grid feeders with high PV penetration are proposed. The investigations are performed with a simulation study using the model of a highly PVpenetrated LV grid, which is a demonstration site within the Meta PV project [12]. The model comprises existing PV systems and additional storage systems.

\section{SYSTEM MODEL}

The fundamental building blocks of a PV system are: the PV array, composed of single PV cells made of semiconducting materials and a PV inverter that converts the power from the PV array into grid-compatible electric 
power. To cope with the excess of PV power generation and low load in LV feeders, in this paper, the standard PV system is enhanced with storage system concepts. One concept is that a storage system can provide voltage support for the whole feeder from a strategically defined location; a second concept relies instead on a number of storage systems to achieve the same target, for example, one storage system on location with PV.

\section{A. LV Grid Analysis}

During high generation and low demand conditions, the active power injected in a feeder can cause voltage rise above the allowed limits, according to [9] and this can be expressed by (2) and (3):

$$
\begin{gathered}
\Delta U=(R \cdot P+X \cdot Q) / V_{G} \\
P=P_{P V}-P_{L}
\end{gathered}
$$

where $R$ and $X$ are the cable resistance and reactance at a certain distance from the transformer, $P$ and $Q$ the active and reactive power exchanged at the $\mathrm{PCC}, V_{G}$ the base grid voltage. Voltage sensitivity analysis can be used for estimating the voltage variation due to active power injection at a certain location. A voltage sensitivity matrix for a grid feeder can be derived for active and reactive power by solving nonlinear load flow equations using the Newton-Raphson algorithm [11]. The same matrix can be used to identify critical locations in relation to load/generation conditions. The most remote node in the feeder, presents the highest sensitivity value, thus it is the most critical location for active power injection in relation to voltage variation.

For mitigating voltage rise problems in a LV grid feeder with PV, various reactive power methods have been already implemented at each PV inverter interface and have been introduced in large scale field tests. The following are the main ones [10]:

a) fixed $\cos \varphi$ (power factor)

b) $\cos \varphi\left(P_{P V}\right)$ : power factor as a function of the active power $\left(\mathrm{P}_{\mathrm{PV}}\right)$ fed into the grid

c) fixed $Q$ (reactive power)

d) $Q(U)$ : reactive power as a function of the voltage at the PCC.

The effectiveness of such methods has been proven and different performances in relation to grid losses and components loading are observable [10]. One of the limitations is that many existing PV installations are not capable of reactive power consumption. The additional utilization of storage systems is an effective approach to reduce voltage rise problems.

In this paper, storage solutions for voltage support and their possible combination with reactive power are being investigated with respect to their effectiveness and their operational requirements.

\section{B. Energy Storage Systems}

Lately, a wide range of energy storage technologies have been investigated by several researches to cope with the intermittency of renewable energy resources (RES). These include electrochemical batteries with various chemistries, supercapacitors, compressed air energy storage, flywheels and others [18]. In this paper, battery-based energy storage systems are assumed for providing voltage support in LV grids. The performance comparison of different battery chemistries, such as energy-to-weight ratio, self-discharge rate and charge/discharge efficiency are out of the scope of the present work, therefore they are not treated.

The charge and discharge equations of a battery system are shown in (4) and (5) [17], where $P_{d}$ is the discharging power of the battery and $P_{c}$ is the charging power; $E$ is the energy stored in the battery at time $t ; \Delta t$ is the duration time of each interval. The two coefficients $\eta_{d}$ and $\eta_{c}$ are the discharge and charge efficiencies respectively.

$$
\begin{aligned}
& E(t+\Delta t)=E(t)-\Delta t \cdot P_{d} / \eta_{d} \\
& E(t+\Delta t)=E(t)+\Delta t \cdot P_{c} \cdot \eta_{c}
\end{aligned}
$$

The operation of the battery system should also take into account power and energy constraints.

The power limits of a battery system can be described by (6) and (7):

$$
\begin{aligned}
& 0 \leq P_{d}(t) \leq P_{d}^{\max } \\
& 0 \leq P_{c}(t) \leq P_{c}^{\max }
\end{aligned}
$$

The same power limits are important for sizing the power converters of the battery system. The storage power ramp rates are therefore generically described by (6) and (7). In this paper, the symbol $P_{s}$ is used to represent the power flow, including the two phases of charge and discharge.

The energy limits of a battery system can be described by (8):

$$
E_{\min } \leq E(t) \leq E_{\max }
$$

where $E_{\min }$ and $E_{\max }$ are the minimum and maximum energy levels stored in the battery respectively. The energy limits, or state of charge limits (SOC), can be set according to the storage application and to the battery technology, however, in this paper, we will refer to (8) as the usable energy window of the storage system, regardless of the optimal energy management of a particular type of battery.

\section{Problem Formulation}

Considering (2), the idea is to introduce in the expression the component $P_{s}$ which represents the storage power by the energy storage system. Therefore, it is possible to rewrite (2) into (9) where the nodal exchanged power $P^{*}$ is, this time, the combination of the load power $P_{L}$, the generated power $P_{P V}$ and storage power $P_{s}$, as indicated in (10):

$$
\begin{gathered}
\Delta U=\left(R \cdot P^{*}+X \cdot Q\right) / V_{G} \\
P^{*}=P_{P V}-P_{L}-P_{S}
\end{gathered}
$$

With the main target of investigating on storage solutions, emphasis is given to the active power component $P^{*}$ rather than $Q$ in (9). Furthermore, the cooperation of storage and reactive power methods is also investigated, assuming different scenarios for reactive power.

In a LV feeder with high penetration of $\mathrm{PV}$, the integration of storage for voltage support can be performed from a single location, or by multiple storage systems at different locations. The first strategy proposed in this paper 
identifies a centralized storage concept, while the second strategy defines a distributed storage concept.

Considering the voltage limit $\mathrm{V}_{\max }$ in a LV feeder, a storage system should be activated in order not to reach the limit in any of the feeder's nodes.

\section{A. Solution Algorithm}

Considering the different locations on which the storage system can be integrated and the voltage sensitivity matrix in Table IV, it is possible to calculate the storage power that lowers the nodal voltages below the limit. The main problem is to identify the minimum storage power $P_{s}$ that meets the voltage target, according to centralized and distributed concepts. This can be implemented with the storage participation in different locations in the grid, or with multiple storage participation. Fig. 1 shows the algorithm proposed in this paper.

The proposed solution is a linear problem. This algorithm is implemented in Matlab and results are checked with PowerFactory load flow simulations. The algorithm can be summarized as follows:

1) Enter the LV grid model under study, with worst case load/generation conditions on each node

2) Run the load flow grid simulation

3) Identify the critical node/s where the voltage is above $\mathrm{V}_{\text {max }}$

4) Add a combination of storage in the LV feeder

5) Solve the objective function for $P_{s}$ which is to find

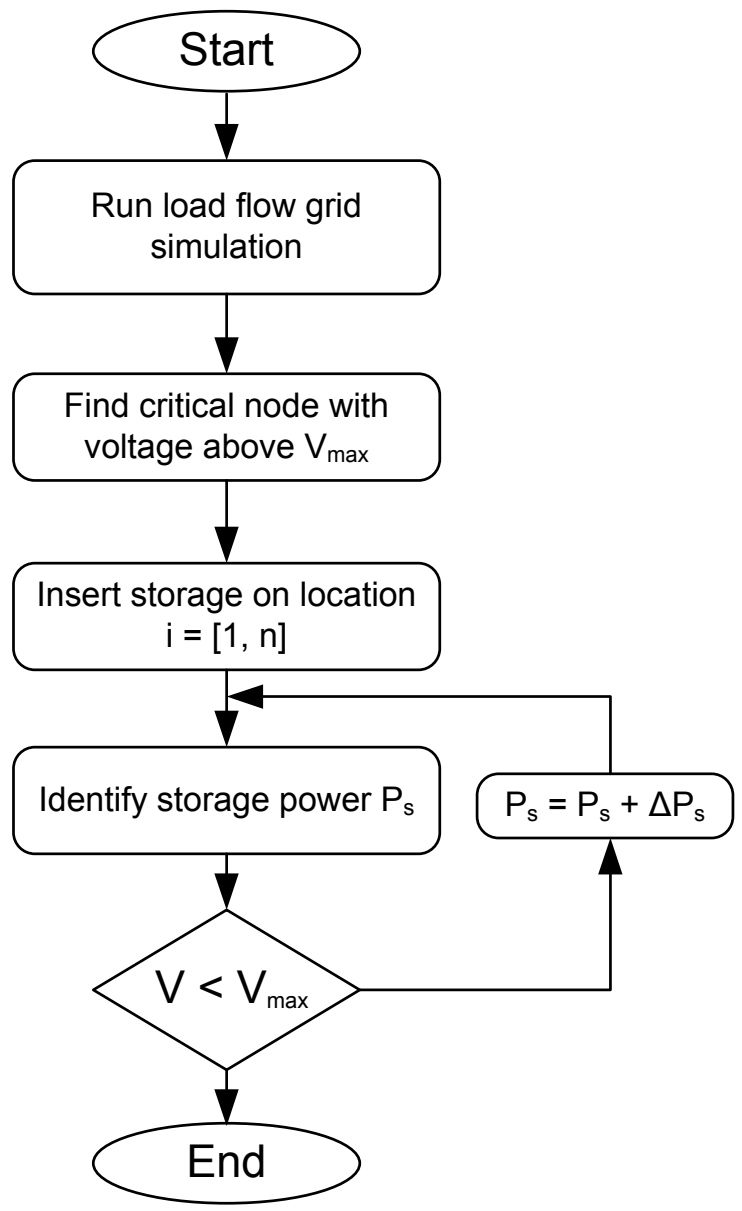

Fig. 1. Proposed method for storage planning the minimum power that keeps the critical voltage below $\mathrm{V}_{\max }$

6) If $\mathrm{V}>\mathrm{V}_{\max }$ update $\mathrm{P}_{\mathrm{s}}$ using $\mathrm{P}_{\mathrm{s}}=\mathrm{P}_{\mathrm{s}}+\Delta \mathrm{P}_{\mathrm{s}}$ and go back to step 5

7) Go back to step 4, set another storage configuration, repeat step 5 and 6 .

The step 7 is repeated until all possible combinations of storage locations are covered, including the cases of multiple storages at the different nodes.

\section{CASE STUdy}

The algorithm implementation and performance assessment is performed for a LV grid with high PV penetration, Fig. 7, with main parameters in Table I. The PV penetration per feeder, which is defined as the ratio of PV installed capacity over the feeder capacity, is indicated in Table II.

TABLE I

LV GRID PARAMETERS

\begin{tabular}{c|c}
\hline Grid type & Urban \\
Transformer & $630 \mathrm{kVA}$ \\
Feeders nr. & 9 \\
Feeder capacity (average) & $195 \mathrm{kVA}$ \\
Cables R/X (average) & 4.6 \\
Number of households & 271 \\
PV installed capacity (kW) & $143.23 \mathrm{~kW}$ \\
Grid topology & Radial \\
\hline
\end{tabular}

TABLE II

FEEDERS CHARACTERISTICS

\begin{tabular}{ccccc}
\hline Feeder & $\begin{array}{c}\text { No. of } \\
\text { households }\end{array}$ & $\begin{array}{c}\text { No. of PV } \\
\text { sources }\end{array}$ & $\begin{array}{c}\text { PV } \\
\text { power/kW }\end{array}$ & $\begin{array}{c}\text { PV penetr. } \\
\%\end{array}$ \\
\hline 2 & 2 & 0 & 0 & 0 \\
3 & 41 & 2 & 10.38 & 5.3 \\
4 & 36 & 2 & 8.80 & 4.5 \\
5 & 19 & 0 & 0 & 0 \\
6 & 18 & 3 & 11.10 & 5.7 \\
9 & 48 & 9 & 39.67 & 20.3 \\
10 & 15 & 2 & 8.80 & 4.5 \\
11 & 33 & 9 & 42.60 & 21.8 \\
12 & 52 & 5 & 21.88 & 11.22 \\
\hline
\end{tabular}

\section{A. Identification of Critical Node}

From the voltage sensitivity analysis performed on the grid, node 7 in the feeder LS11 of Fig. 2 is found the most critical location in the grid. The voltage sensitivity to active power matrix for feeder LS11 is shown in Table III.

TABLE III

VOLTAGE SENSITIVITY MATRIX

\begin{tabular}{c|ccccccc}
$\begin{array}{c}\mathrm{dV} / \mathrm{dP} \\
\text { p.u./MW }\end{array}$ & $\mathbf{1}$ & $\mathbf{2}$ & $\mathbf{3}$ & $\mathbf{4}$ & $\mathbf{5}$ & $\mathbf{6}$ & $\mathbf{7}$ \\
\hline $\mathbf{1}$ & 0.37 & 0.36 & 0.37 & 0.35 & 0.35 & 0.34 & 0.34 \\
$\mathbf{2}$ & 0.37 & 0.72 & 0.36 & 0.71 & 0.71 & 0.69 & 0.72 \\
$\mathbf{3}$ & 0.36 & 0.36 & 0.76 & 0.35 & 0.35 & 0.34 & 0.35 \\
$\mathbf{4}$ & 0.36 & 0.72 & 0.36 & 0.91 & 0.91 & 0.88 & 0.88 \\
$\mathbf{5}$ & 0.36 & 0.72 & 0.36 & 0.89 & 1.35 & 0.71 & 0.69 \\
$\mathbf{6}$ & 0.36 & 0.71 & 0.36 & 0.91 & 0.89 & 0.98 & 0.98 \\
$\mathbf{7}$ & 0.36 & 0.71 & 0.35 & 0.89 & 0.68 & 0.88 & 1.51 \\
\hline
\end{tabular}

Using 6-days measurements-based load/generation profiles, representing the worst case scenario of high generation and low load conditions, gives the voltage profiles of Fig. 3. The voltages on the nodes with PV, 2, 4, 5 


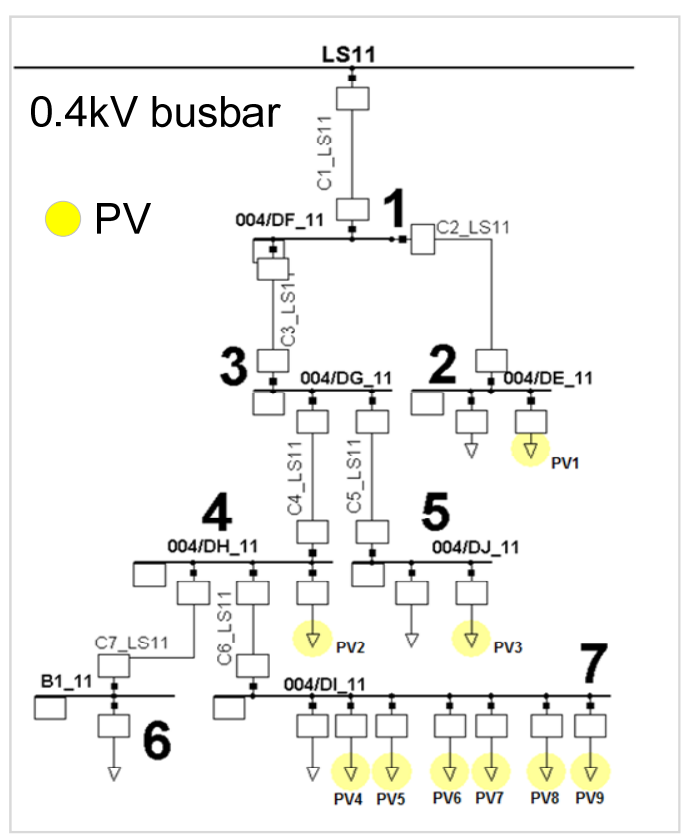

Fig. 2. Single line diagram of feeder 11

and 7 , are displayed respectively, emphasizing voltage rise and unbalance problems.

To evaluate the storage requirements for voltage rise mitigation in the feeder, under the described scenario, the two concepts of centralized and distributed storage are investigated.

\section{B. Centralized Storage}

The first concept addressed is centralized storage (CS); this is implemented by placing a single storage unit on a feeder node. With this concept, only one storage device is present in the feeder, providing the voltage support function required.

The control of the storage under the CS concept is according to $P_{s}=f(U)$, where $U$ is the most critical nodal voltage in the feeder. In this case study, three different scenarios are investigated for the CS concept: CS1, storage on node 2; CS2, storage on node 4; CS3, storage on node 7.

The proposed algorithm in Fig. 1 is used to estimate the power requirement for the different options.

\section{Distributed storage}

The second investigated concept is the distributed multiple storage concept (DS). With this concept, a storage device is integrated at each PV location in the feeder. In relation to the algorithm of Fig. 1, the DS concept corresponds to the combination of storage power $\mathrm{P}_{\mathrm{S} i}$ by all nodes with PV that leads to a voltage below $V_{\max }$ in the whole feeder. The control of the storage devices under the DS concept is done according to $P_{S i}=f\left(P_{P V}\right)$. Assuming the case of all PV inverters with same nominal power and same solar radiation, the storage contribution $\mathrm{P}_{\mathrm{S} i}$ from each storage device would be also the same for all. The DS scenario proposed prioritizes the equal participation from all PV power producers.

\section{Combined Storage and Reactive Power}

From the two main storage concepts, three variants are studied that consider the reactive power combination with the energy storage systems. The investigated combined storage and reactive power options are as follows:

- $\quad$ CS3 concept with all PV inverters working with fixed $\mathrm{PF}=0.95$ (CS3-distr. Q)

- $\quad$ CS3 concept with reactive power capability, all PV inverters with $\mathrm{PF}=1(C S 3$ with $Q)$

- DS concept with all PV inverters working with $\mathrm{PF}=0.95,(D S$ with $Q)$

The power factor PF is defined as [13]:

$$
P F=\frac{P}{S}=\cos \varphi
$$

where $P$ is the real power flow (in watts), $S$ is the apparent power flow (in volt-amperes, VA) and $\varphi$ is the angle difference between the voltage and current waveforms on a given phase. The power factor is continuously variable between 0 and 1 and in this case study it indicates a component that consumes reactive power (in VAr).

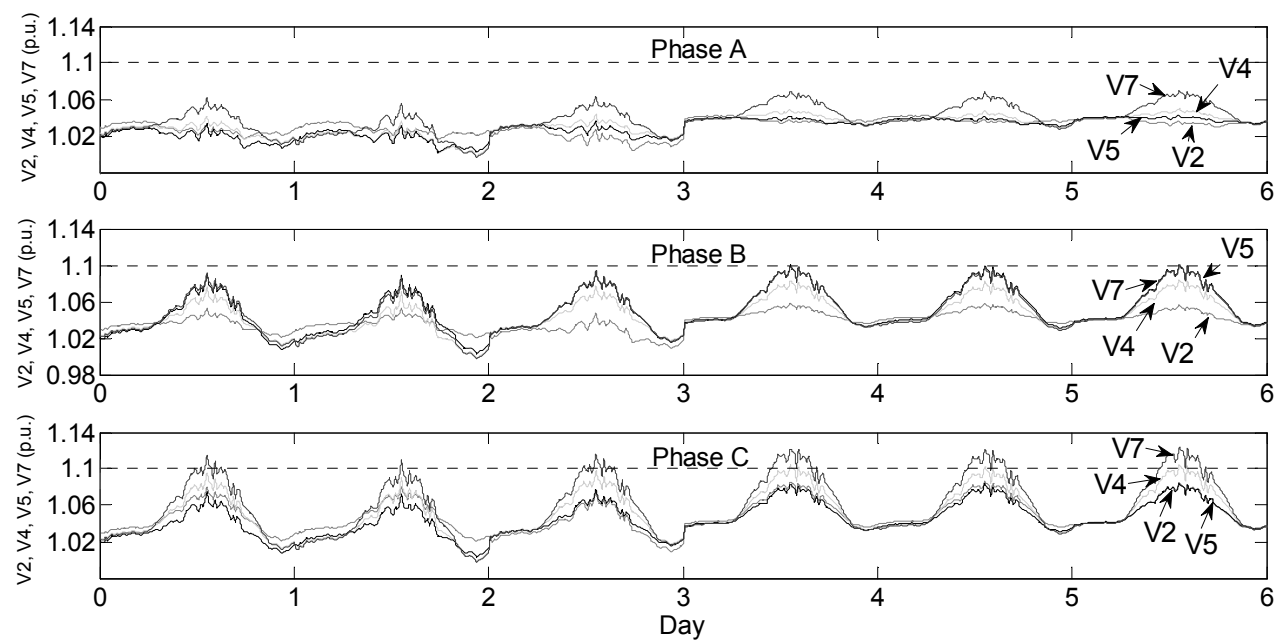

Fig. 3. Phase voltages on feeder 11 with PV without voltage support 


\section{Simulation Results}

Dynamic grid simulations are performed for the LV feeder with the different storage options. The results for the $6^{\text {th }}$ day are summarized in Table IV. During the $6^{\text {th }}$ day, a worst case scenario occurs in relation to low load and high generation conditions. In Fig. 4, the storage power for CS1, $\mathrm{CS} 2, \mathrm{CS} 3$ and DS are depicted for the 6-days interval. It is evident that placing a CS on node $7, \mathrm{CS} 3$, leads to a minimum aggregated power and energy requirement, while a minimum device power and energy level is obtainable with the DS concept.

The results of combined storage and reactive power options are depicted for the $6^{\text {th }}$ day in Table V. The comparison with the "only" storage options is given in Fig. 5 and Fig. 6, where the CS3 and DS results are depicted as a reference. With all PV inverters consuming reactive power, the storage power and energy levels are significantly reduced in both concepts of DS and CS. In Fig. 5 and 6, this is particularly evident for the options named "DS with Q" and "CS3 - distr. Q".

TABLE IV

SUMMARY OF STORAGE RESULTS

\begin{tabular}{c|cccc}
$\begin{array}{c}\text { Storage } \\
\text { option }\end{array}$ & $\begin{array}{c}\text { Total Ps } \\
(\mathbf{k W})\end{array}$ & $\begin{array}{c}\text { Ps/device } \\
\mathbf{( k W )}\end{array}$ & $\begin{array}{c}\text { Total E } \\
\mathbf{( k W h )}\end{array}$ & $\begin{array}{c}\text { E/device } \\
(\mathbf{k W h})\end{array}$ \\
\hline CS1 & 11.1 & 11.1 & 30.2 & 30.2 \\
CS2 & 4.75 & 4.75 & 12 & 12 \\
CS3 & 3 & 3 & 7 & 7 \\
DS & 4.2 & 0.9 & 10.2 & 2.5 \\
\hline
\end{tabular}

TABLE V

COMBInED Storage AND REACTIVE POWER RESUlts

\begin{tabular}{c|cccc}
$\begin{array}{c}\text { Storage } \\
\text { option }\end{array}$ & $\begin{array}{c}\text { Total } \\
\text { Ps } \\
(\mathbf{k W})\end{array}$ & $\begin{array}{c}\text { Ps/device } \\
\mathbf{( k W )}\end{array}$ & $\begin{array}{c}\text { Total E } \\
\mathbf{( k W h )}\end{array}$ & $\begin{array}{c}\text { E/device } \\
\text { (kWh) }\end{array}$ \\
\hline DS with Q & 4.5 & 0.5 & 2.7 & 0.3 \\
CS3 distr. Q & 1.9 & 1.9 & 1.0 & 1.0 \\
CS3 with Q & 2.8 & 2.8 & 4.1 & 4.1 \\
\hline
\end{tabular}

With a CS option providing a fixed amount of reactive power, "CS with Q", the storage power and energy are decreased accordingly. For this case study, Q is chosen of 1 $\mathrm{kVAr}$, which is the level or reactive power obtainable with a $\mathrm{PF}$ of 0.95 and active power $\mathrm{P}_{\mathrm{S}}$ of $3 \mathrm{~kW}$ (which is the CS3 power requirement).

The energy levels of the storage devices under the

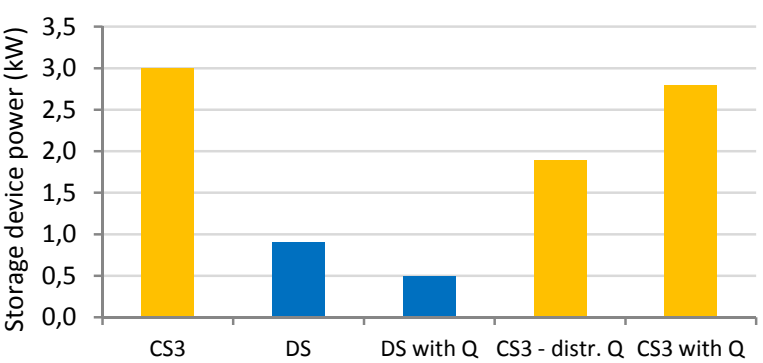

Fig. 5. Storage device power for all options

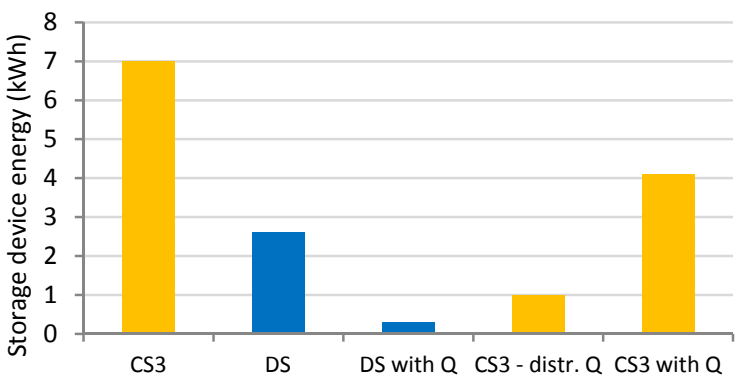

Fig. 6. Storage device energy for all options

different concepts can be put in relation to local consumption. In particular, under the DS concept, local consumption is possible in such a way that the energy stored for voltage support can be used by PV system owners to supply any domestic appliances, during off-generation hours. On this point, there is space for further investigations.

\section{CONCLUSIONS}

In this paper, different storage planning options for LV grids with high share of PV have been proposed.

Distributed storage solutions at each PV location have shown that a relatively small power and energy are needed to provide voltage support, securing voltage quality according to standard EN 50160.

The identification of the best location under the centralized storage concept is solved with an iterative method, based on voltage sensitivity analysis. A CS option at the end of the feeder is found as the option with minimum power/energy requirement for voltage support.

To minimize storage power and energy for CS and DS, all

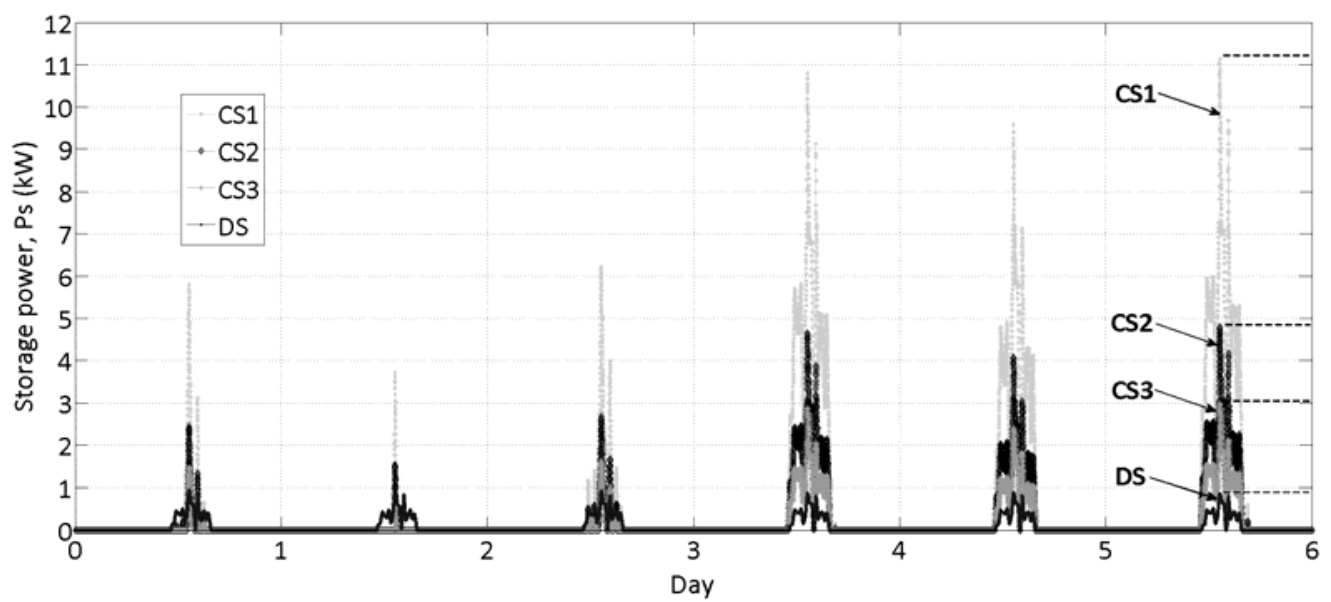

Fig. 4. Storage device power for the $C S$ and $D S$ 


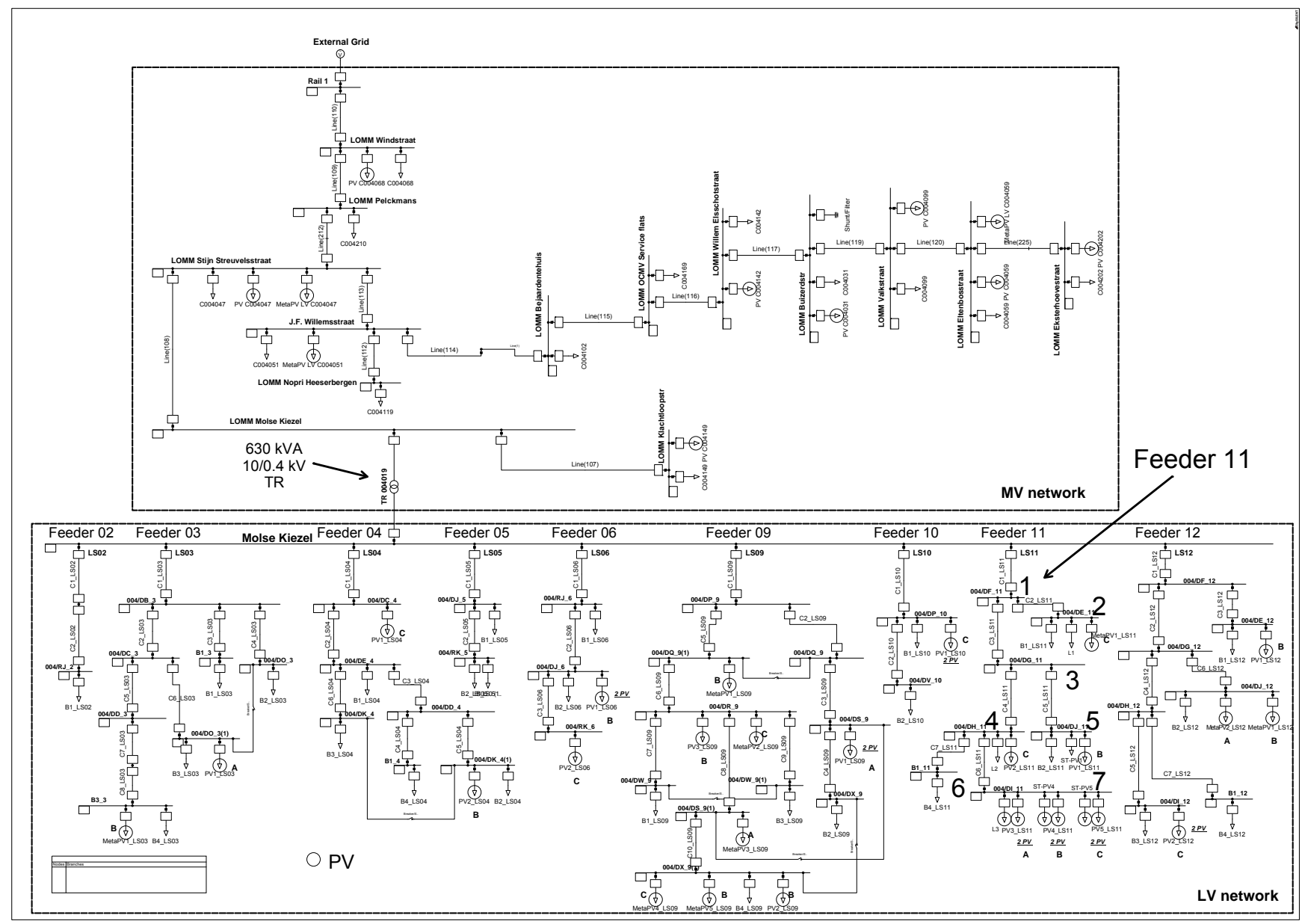

Fig. 7. Single-line diagram of the LV Belgian grid

storage options can cooperate with reactive power methods at the PV interface. Having all PV inverters operating at the constant power factor of 0.95 has shown to significantly lower the required storage power and energy levels.

The storage solutions proposed can potentially relieve the DSOs from voltage quality concerns due to high PV generation and low demand periods. Furthermore, the deployment of such storage solutions would limit the practice of power curtailment, thus allowing an increased PV penetration. The discharging phase of the storages, which is not treated in this work, offers the opportunity of self-consumption in the centralized and distributed concept.

\section{REFERENCES}

[1] European Commission, "20 20 by 2020 Europe's climate change opportunity", COM (2008) 30 final, Brussels, 2008.

[2] V. F. Martins, and C. L. T. Borges, "Active Distribution Network Integrated Planning Incorporating Distributed Generation and Load Response Uncertainties", in IEEE Transactions on Power Systems, vol. 26, no. 4, pp. 2164-2172, 2011

[3] H. A. Gil, G. Joos, "Models for Quantifying the Economic Benefits of Distributed Generation", in IEEE Transactions on Power Systems, vol. 23 , no. 2 , pp. $327-335,2008$.

[4] S. Paudyal, C. A. Cañizares, and K. Bhattacharya, "Optimal Operation of Distribution Feeders in Smart Grids", in IEEE Transactions on Industrial Electronics, vol. 58, no. 10, pp. 4495$5503,2011$.

[5] X. Liu, A. Aichhorn, L. Liu, H. Li, "Coordinated Control of Distributed Energy Storage System With Tap Changer Transformers for Voltage Rise Mitigation Under High Photovoltaic Penetration", in IEEE Transaction on Smart Grids, vol. 3, no. 2, pp. 897-906, 2012.

[6] M. Delfanti, M. Merlo, M. Pozzi, V. Olivieri, and M. Gallanti, "Power flows in the Italian distribution electric system with Dispersed Generation", in Conf. Proceedings of 20th International Conference and Exhibition on Electricity Distribution - Part 1, CIRED 2009, 2009.

[7] N. Etherden, and M. H. J. Bollen, "Increasing the Hosting capacity of Distribution Networks by Curtailment of Renewable Energy Sources", in Conf. Proceedings of IEEE PowerTech, Trondheim, 2011.

[8] Standard EN 50160, "Voltage Characteristics of electricity supplied by public distribution networks", Cenelec 2010.

[9] P. Carvalho, P. Correia, and L. Ferreira, "Distributed Reactive Power Generation Control for Voltage rise Mitigation in Distribution Networks", in IEEE Transactions on Power Systems, vol. 23, no. 2, pp. 766-772, 2008.

[10] Y. T. Fawzy, D. Premm, B. Bletterie, and A. Gorsek, "Active contribution of PV inverters to voltage control - from a smart grid vision to full-scale implementation", in Journal of Elektrotechnik \& Informationstechnik, vol. 128, no. 4, pp.110-115, 2011.

[11] E. Demirok, P. Casado Gonzalez, K. H. B. Frederiksen, D. Sera, P. Rodriguez, and R. Teodorescu, "Local Reactive Power Control Methods for Overvoltage Prevention of Distributed Solar Inverters in Low-Voltage Grids", in IEEE Journal of Photovoltaics, vol. 1, no. 2, pp. 174-182, 2011.

[12] B. Blazic, I. Papic, B. Uljanic, B. Bletterie, C. Dierckxsens, K. De Brabandere, W. Deprez, Y. T. Fawzy, "Integration of Photovoltaic Systems with Voltage Control Capabilities into LV networks", in conf. proc. of $1^{\text {st }}$ International Workshop of Solar Power into Power Systems, 2011.

[13] C. A. Hill, M. C. Such, D. Chen, J. Gonzales, W. M. Grady, Battery Energy Storage for Enabling Integration of Distributed Solar Power Generation, in IEEE Transactions on Smart Grid, vol. 3, no. 2, pp. $850-857,2012$.

[14] M. Ragwitz, A. Held, E. Stricker, A. Krechting, G. Resch, C. Panzer, Recent experiences with feed-in tariff systems in the EU - A research paper for the International Feed-in Cooperation, 2010, online report.

[15] M. Braun, K. Budenbender, M. Perrin, H. Collin, Z. Feng, and D. Magnor, Photovoltaic Self-Consumption in Germany - Using Lithium-Ion Storage to Increase Self-Consumed Photovoltaic Energy, in Conf. Proc. of $24^{\text {th }}$ European Photovoltaic Solar Energy Conference, 2009. 
[16] Renewable Energy Sources Act (EEG), "Tariffs, degression and sample calculations pursuant to the new Renewable Energy Sources Act", online report, 2012.

[17] Y. Rffonneau, S. Bacha, F. Barruel, and S. Ploix, "Optimal Power Flow Management for Grid Connected PV Systems With Batteries", in IEEE Transactions on Sustainable Energy, vol. 2, no. 3, pp. 309320, 2011.

[18] J. P. Barton, and D. G. Infield, "Energy storage and its use with intermittent renewable energy", in IEEE Transactions on Energy Conversion, vol. 19, no. 2, pp. 441-448, 2004.

\section{BIOGRAPHIES}

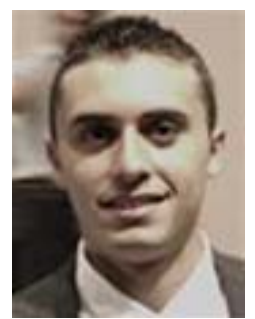

systems.
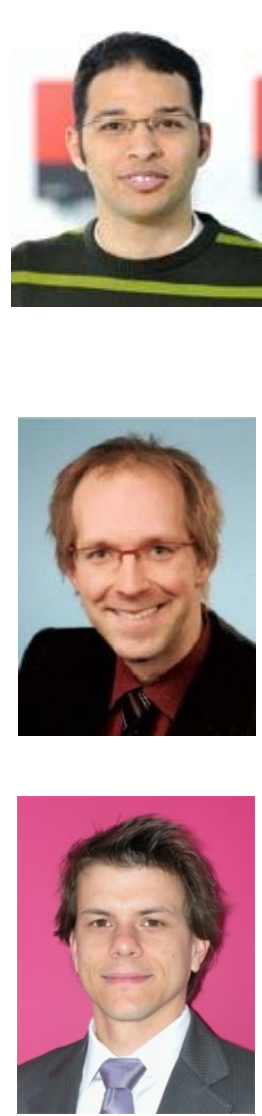

Francesco Marra received the electronic and mechatronic engineering degree from Polytechnic of Turin, Italy, in 2006 and 2008, respectively. He is currently within the Electrical Engineering department of the Technical University of Denmark, where he is pursuing the Ph.D. degree. Previously, he has been within SMA Solar Technology working on PV integration and energy storage. His fields of interest include grid integration of renewable energy and control

Yehia Tarek Fawzy received his BSc in 2005 in Power Engineering at the University of Ain Shams, Cairo, Egypt. Afterwards he receivied his M.Eng. in control and Mechatronics at the university of Paderborn, Germany in 2008. Since then he is working for SMA Solar Technology AG as a systems engineer. His activities are focused to development and evaluation of control concepts for grid integration of PV systems. His research interests include analysis, modelling and optimization of PV system behaviour in terms of network stability and power quality.

Thorsten Bülo (Member, IEEE) received the BSc, $\mathrm{MSc}$ and $\mathrm{PhD}$ degrees, all in electrical engineering, from the University of Kassel, Germany in 2002, 2004 and 2010, respectively. $\mathrm{He}$ is currently manager of the team Grid Integration of the SMA Solar Technology AG in Niestetal, Germany.

Boštjan Blažič received the $\mathrm{BSc}, \mathrm{MSc}$ and $\mathrm{PhD}$ degrees, all in electrical engineering, from the University of Ljubljana, Slovenia, in 2000, 2003 and 2005 , respectively. He is presently an assistant professor at the Faculty of Electrical Engineering, Ljubljana. His research interests encompass power quality, distributed generation, mathematical analysis and control of power converters. 